\title{
Investigation of Structural, Morphological, Resistivity of Novel Electrical Insulator: Industrial Wastes
}

\author{
M.K. Panigrahi a, ${ }^{\star}$
}

a PG Department Materials Science, Maharaja Sriram Chandra Bhanja Deo University, Keonjhar Campus, Odisha, India.

*Corresponding author Email: muktikanta2@gmail.com

DOI: https://doi.org/10.34256/bsr2116

Received: 20-03-2021; Accepted: 16-05-2021; Published: 22-05-2021

Abstract: In the present study, the effect of china clays on the sintering, strength and dielectric behavior of electrical ceramic fly ash/china clay (FA/CC) composite insulator is investigated. The different composition of samples containing different china clay (CC) contents of $10,20,30,40$, and $50 \%$ are prepared using the uniaxial pressure technique applying $10 \mathrm{MPa}$ pressure. At $1200{ }^{\circ} \mathrm{C}$, for the composition having $40 \mathrm{wt} \%$ china clays, the maximum resistivity is calculated and is $39.5 \times 10^{7} \Omega \mathrm{m}$. The composite is highly competence with china claysbased insulators. Further, the prepared composite is also analysed using different characterization technique such as $\mathrm{x}$-ray diffraction, field emission scanning electron microscopy with energy dispersive analysis, fourier transformation infra-red spectroscopy, dielctric, and thermo gravimetric analysis. Frequency dielectric value of the composite is estimated at room temperature in the frequency range of $1-500 \mathrm{kHz}$ at room temperature. According to the resistivity and dielectric properties, the composite has enormous potential for the electrical insulator application.

Keywords: Industrial Wastes, Fly Ash (FA), China Clay (CC), Mulite, Quartz, Resistivity, Dielectric

\section{Introduction}

After studying the chemical and physical properties of Fly ash [1-3] from thermal power plants and red mud from aluminum refineries [4, 5], we found that it should not only be treated as a simple waste which mainly creates environment problem, health problem and reduces fertility of soil [1-5]. Therefore, the scientific communities are devoted to continue the research using industrial wastes to make the useful materials to the society for economic benefits. The one of the useful materials is electrical materials [6-8]. In the electrical point of view, Insulators have great importance in everyday life as it makes our life easy, safe and shock free. We use varieties of insulators knowingly or unknowingly for different purposes. Electrical pin used in electrical poles is also a same kind of insulator [6-8]. Similarly, dielectrics are also very important for instruments that we use not only in our day-to-day life but in high value in high technology applications such as defence [6], microwave [7], capacitors [8], etc. We have invented a tunable material which has a great application in microwave engineering [7], so it can be used as a phase shifter [9], filter [10] and resonator [11] etc. It can also be used in manufacturing radomes. All of these are of high value for defence applications [6], and presently these electronic instruments are not manufactured in India, and are imported from foreign countries. Hence, it is important to produce developed electronic materials from industrial wastes. Therefore, it will facilitate for the production and development of these appliances in our country. Thus, it will save foreign exchange and promote export potential of the electronic goods.

In this work, fly ash based composite materials are prepared by solid state through bisquetting followed with sintering process using fly ash, china clays, dextrin with small amount of water as precursors. Frequency dependence dielectric constant (k) and resistivity value of the material is estimated at room temperature. Structural and morphological with EDS analyses of the raw materials and the composites are explored. In addition, thermogravimetric analysis of the as-prepared composite is done. 


\section{Experimental Section}

\subsection{Materials and Method}

Fly ash is collected from NALCO, Damanjodi, Odisha. China clays are purchased from Merck, India Dextrin $\left(\mathrm{C}_{6} \mathrm{H}_{10} \mathrm{O}_{5}\right)$ n. $\left.\mathrm{xH}_{2} \mathrm{O}\right)$ is purchased from Loba chemicals. Water $(6 \%)$ is needed to prepare the green sample(s). The chemical composition of Fly ash and China clays are presented in Table 1.

\subsection{Preparation of Test Samples}

Preparation of Sintered Fa/Cc Composite [12]

Fly ash is grinded in a ball mill for $5 \mathrm{~h}$ and is sieved in 240 meshes. Then, the fly ash is dried in heating oven at $120^{\circ} \mathrm{C}$ in $2 \mathrm{~h}$ for removing moisture. Different sets of $F A / C C$ composite reaction are designed and are presented in Table 1. In each set, appropriate proportion of Fly ash and cchina clays are mixed together and grinded properly. $0.05 \%$ dextrin followed by $6-10 \%$ water is added to the mixture and is grinded. Grinding is continued for $1 \mathrm{~h}$. This sample is called green samples. It is ready for making pellet. Pellets are prepared using universal testing machine (UTM) with pelletizer. The assembled of pelletizer are cleaned before use. The green sample is put in cleaned pelletizer. $10 \mathrm{MPa}$ pressure is applied to it and is left for five minutes for green sample compaction. After that, the pellet sample is removed from the pelletizer. Thicknesses and diameter of as-prepared pellets are measured and is $1.1 \mathrm{~mm}$ and $10 \mathrm{~mm}$, respectively. The green pallet is bisquetting at $900{ }^{\circ} \mathrm{C}$ for $1 \mathrm{~h}$ followed by sintering at $1200{ }^{\circ} \mathrm{C}$ for $2 \mathrm{~h}$. During bisquetting, dextrin and intacted water is removed. The entire process of the composite preparation as flow chart is shown in Figure 1. These sintered samples are read to use for different measurement.

Table 1 Chemical composition of Fly ash and China clays

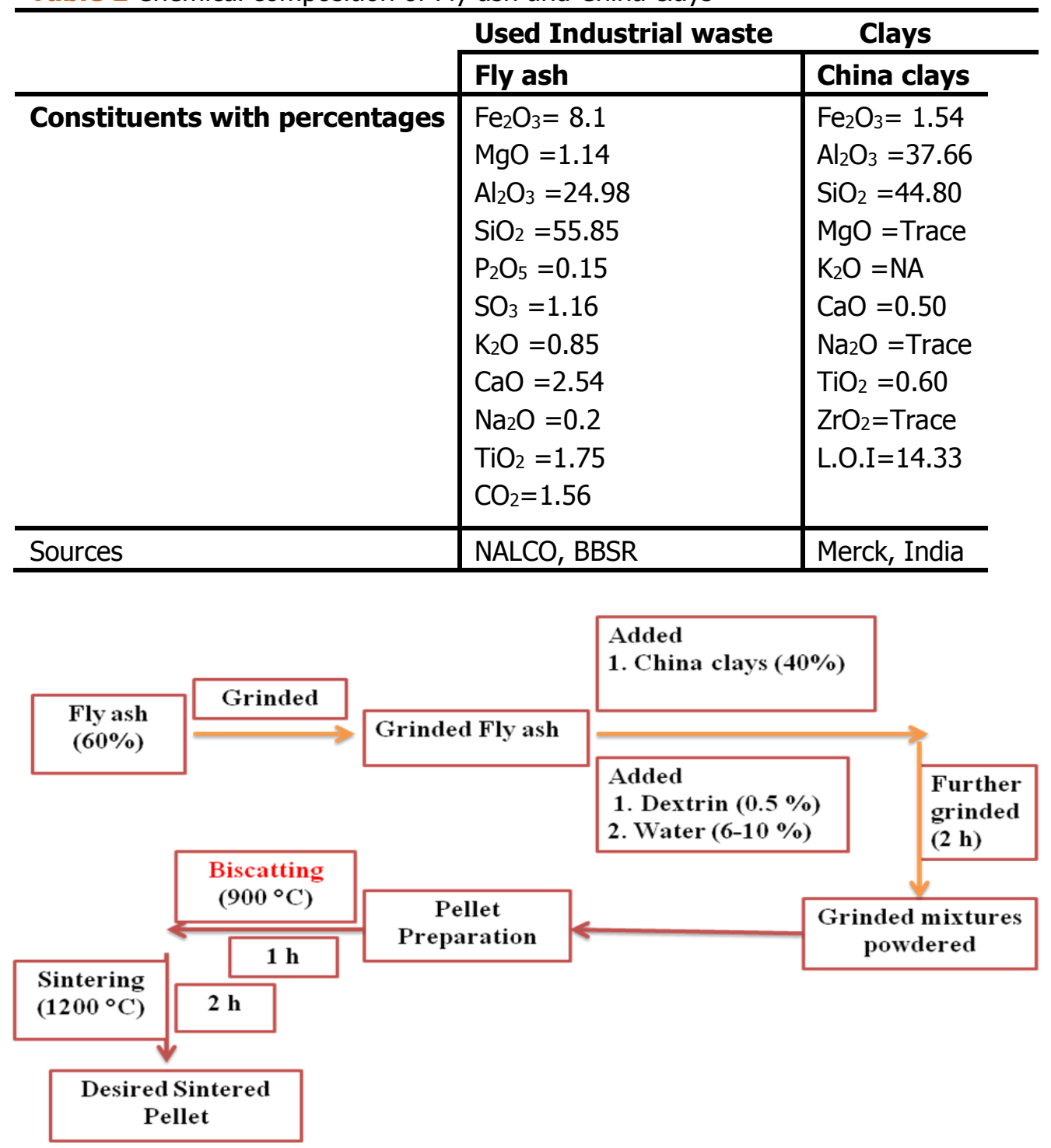

Figure 1. Sintered Fly ash (60\%)/Chaina clay (40\%) composite preparation flow chart 


\subsection{Characterization Techniques}

$X$-ray diffraction experiments $F A, C C$, and sintered $\mathrm{FA} / \mathrm{CC}$ composite are performed using a (Phillips PW-1710 advance wide angle Xray diffractometer, Phillips PW-1729 X-ray generator, CuKa radiation, $\lambda=0.154 \mathrm{~nm}$ ). The generator is operated at $40 \mathrm{kV}$ and $20 \mathrm{~mA}$. The powder samples are placed on a quartz sample holder at room temperature and are scanned at diffraction angle $2 \theta$ from $10^{\circ}$ to $70^{\circ}$ at the scanning rate of $2 \%$ min.

FTIR spectra of $\mathrm{FA}, \mathrm{CC}$, and sintered $\mathrm{FA} / \mathrm{CC}$ composite are recorded on a Thermo Nicolt Nexus 870 spectrophotometer in the range $400-4000 \mathrm{~cm}^{-1}$. The instrument settings are kept constant (50 scan at $4 \mathrm{~cm}^{-1}$ resolution, Absorbance measurement mode). FTIR test samples i.e., pallet is prepared by compression molding using a pelletizer and potassium Bromide $(\mathrm{KBr})$ with small amounts of test powder samples. Before running the samples, a background spectrum is collected. Then, the pallet is put in a sample holder and data are collected.

Surface morphologies of FA, CC, and sintered $\mathrm{FA} / \mathrm{CC}$ composite are analysed by field emission scanning electron microscopy (FESEM) using (Carl Zeiss Supra 40). Before FESEM experiment, gold coating is done via sputtering technique. Operating voltage of the microscope is maintained at $30 \mathrm{kV}$.

Dielectric measurement of sintered FA/CC composite is measured at room temperature using impedance analyzer (PSM1735 model, Newtons4th Ltd, UK). For this measurement, pellet samples (circular surface) are taken. Probe is contacted on aluminium foils. The diameter of probe is $2.8 \mathrm{~mm}$. Dielectric constant $(k)$ is calculated using the relation [13]

$$
k=\left(\frac{C \times d}{A \varepsilon_{0}}\right)
$$

Where $\mathrm{A}$ is the area of electrode $=\frac{\pi}{4} D^{2}\left(\mathrm{~m}^{2}\right)$, $\mathrm{d}$ is the thickness of prepared samples $(m)$, the $\varepsilon_{0}$ is permittivity in vacuum $=8.854 \times 10^{-12} \mathrm{~F} / \mathrm{m}$ and $\mathrm{C}$ is the capacitance in farad. The frequency range is $10 \mathrm{~Hz}$ to $500 \mathrm{kHz}$.

TGA analysis of sintered FA/CC composite is performed using a Perkin Elmer Pyris Diamond analyzer. The test is done in nitrogen environment and heating rate is $10^{\circ} \mathrm{C} / \mathrm{min}$. For this test, $8 \mathrm{mg}$ samples are taken.

\section{Results and Discussion}

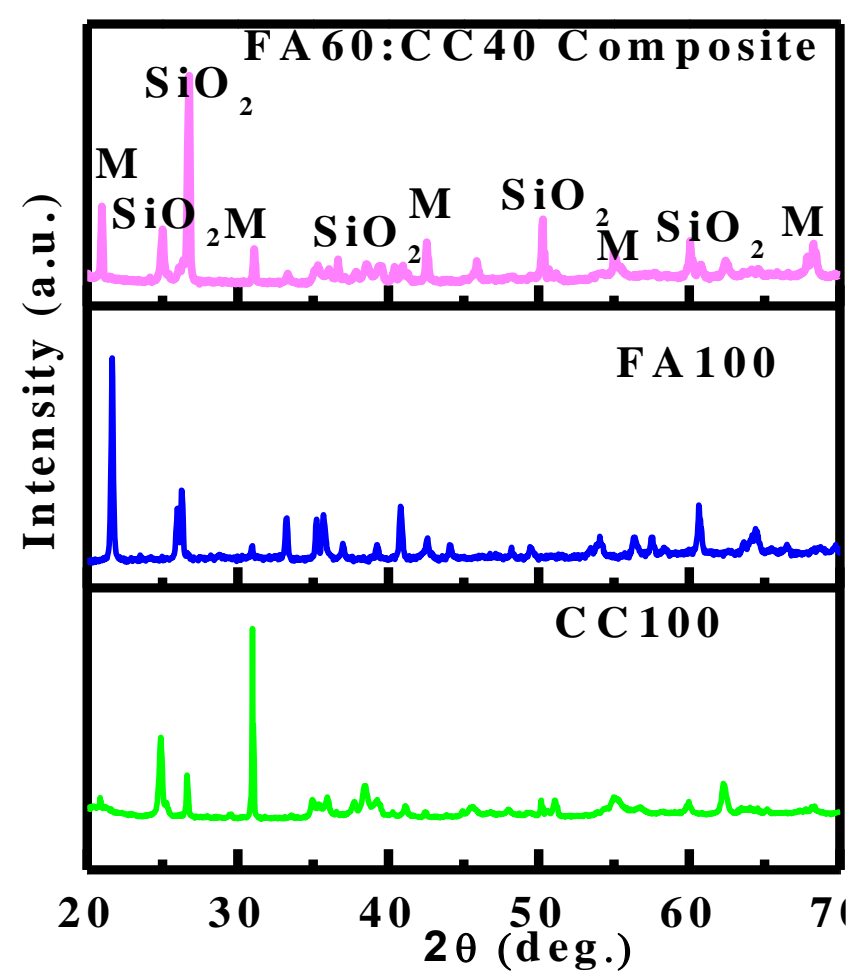

Figure 2. XRD plot of FA100 [14], China clays [15], Sintered Fly ash/China Clay composite (C)

Figure 2 show superimposed XRD pattern obtained from three different types of samples i.e., prepared with as-received fly ash (FA100), Chaina clays (CC100) and Fly ash/China Clay (FA60:CC40) composite. Sharp XRD peaks can be seen in all superimposed XRD curves. It can infer that the materials have crystalline phases. Sharp peaks in the materials are identified to be quartzite and mulite phases. XRD pattern of the composite is crystalline phases. This is formed due to chemical and thermal treatment of used components. The phases show the presence of more amount of mullite in the composite sample with few peaks of silica. Alumina and silica present in both Flyash and china clay combined to form Mullite. However, presence of some peaks of silica in XRD shows that some of these have not formed Mullite, and it can be converted to $100 \%$ Mullite by sintering at some higher temperature or by adding some alumina to Flyash. These observations are highly interesting because mullite is a well-known electrical and thermal insulator, which is used in many industrial and commercial purposes.

FTIR spectra of the Fly ash, China clay, and FA/CC composite material are shown in Figure 3. FTIR spectra indicate the presence of different absorption bands in each category of material. 


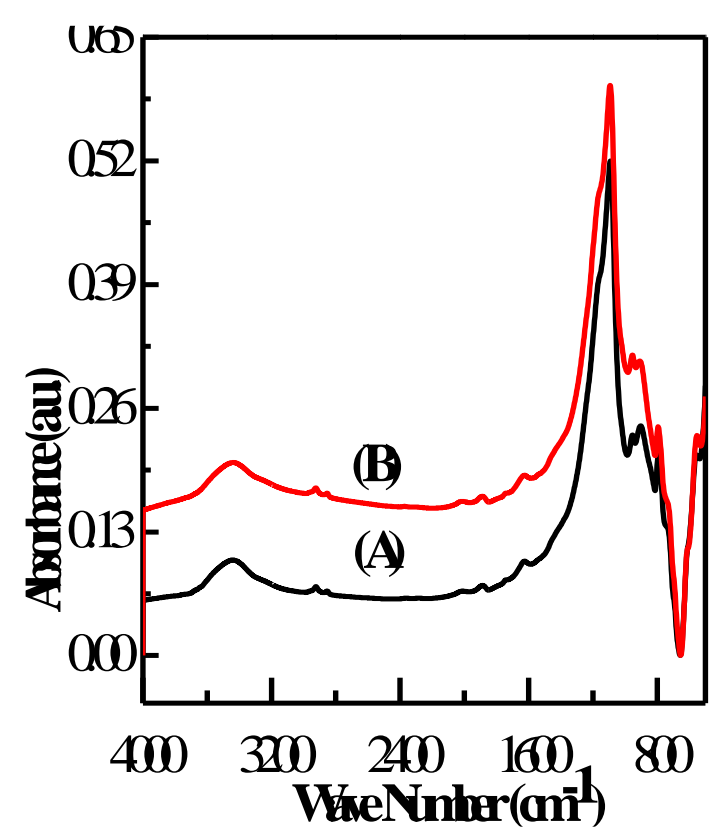

Figure 3. FTIR of Fly ash [16], China clays [17], Sintered Fly ash/China Clay composite (C)
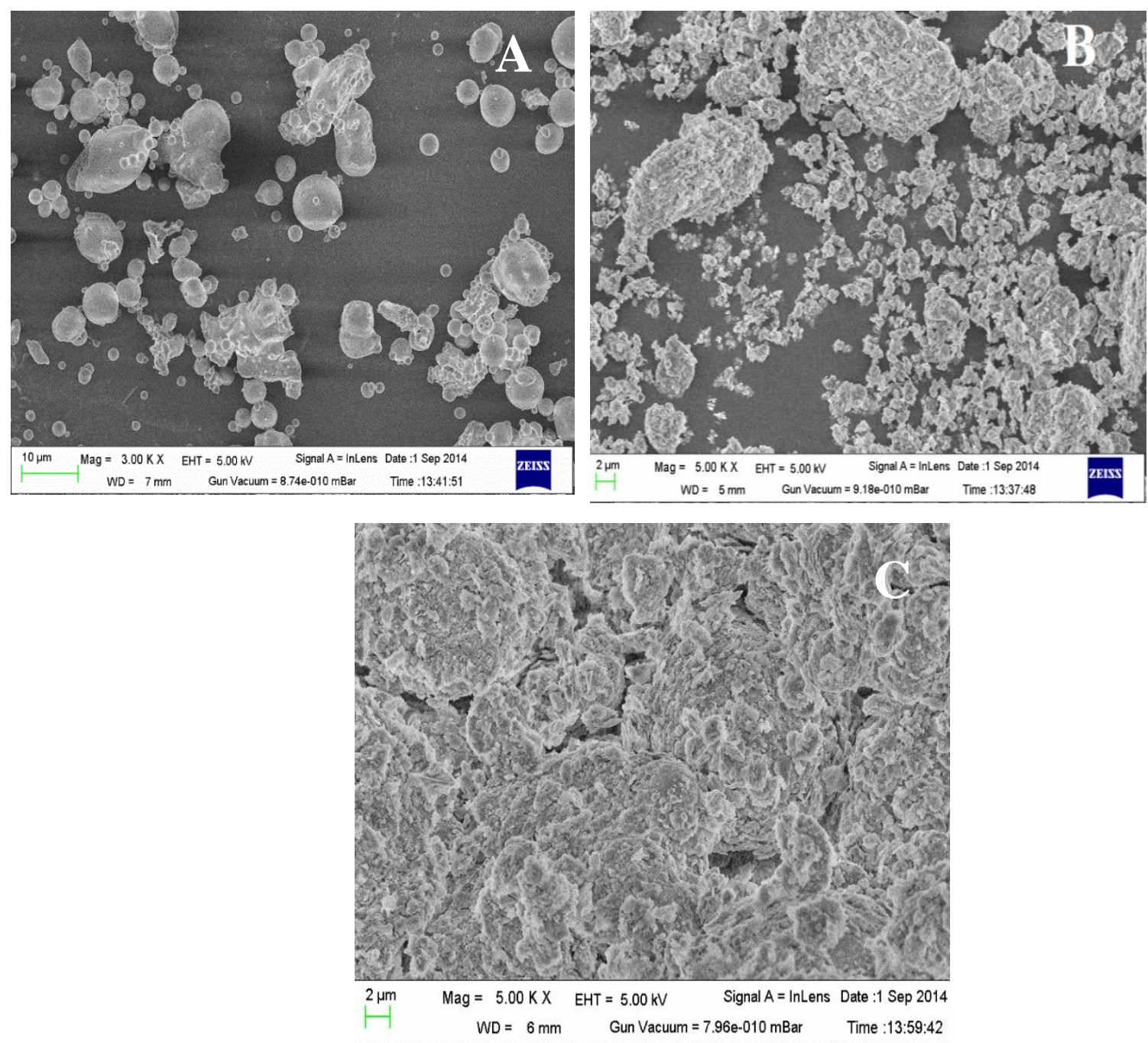

Figure 4 FESEM images of Fly ash (A), China clays (B), Sintered Fly ash/China Clay composite (C)

Fig. 3A indicates the presence of different absorption bands occurring at different wave numbers i.e., 3441, 2918, 1823, 1638, 1117 and $907 \mathrm{~cm}^{-1}$. Bands are in agreement with stretching vibrations of $\mathrm{O}$ -
$\mathrm{H}$ bonds (3441 $\mathrm{cm}^{-1}$ wave number) and $\mathrm{H}-\mathrm{O}-\mathrm{H}$ bending vibrations (1638 $\mathrm{cm}^{-1}$ wave number) of interlayer adsorbed $\mathrm{H}_{2} \mathrm{O}$ molecule [16]. The hydroxyl-stretching band of water plays an important role and peak shift of 
the FTIR spectra is significant. Absorption band ensue at $1117 \mathrm{~cm}^{-1}$ wave number is attributed to $\mathrm{Si}-\mathrm{O}$ band and signifies the occurrence of silicate groups. Presences of $\mathrm{Al}^{3+} \mathrm{O}^{2-}$ absorption bands are also indicated near $907 \mathrm{~cm}^{-1}$ wave number [17].

FESEM images of Fly ash (A), China clays (B), and sintered Fly ash/China clay composite (at $1200^{\circ} \mathrm{C}$ ) are shown in Fig. 4(A-C). It can be seen from FESEM image of FA (Fig. 4A) that the Fly Ash is mainly constituted by irregular shape of spheres but with a regular smooth texture. Also, some quartz particles, residue of un-burnt coal or some vitreous unshaped fragments could be seen. In Figure $\mathbf{4 B}$, it shows the china clays, which is flake like structure. FESEM image of sintered Fly ash/china clay composite shows nonuniform segregated structure with small pores. This is formed due to the interaction of china clays (CC) into the FA spheres and is expected to be advantageous for higher crystallinity. This indicates the formation of mulite phase.

EDS analyses are done during the FESEM studies (Figure 5). The elements such as $\mathrm{O}, \mathrm{Al}, \mathrm{Si}, \mathrm{Fe}$, $\mathrm{Ca}$, and $\mathrm{Mg}$ are present both in China Clays, Fly As, and the composite except $\mathrm{Na}$, $\mathrm{Ti}$, and K (Fig. 5). $\mathrm{Na,}$ $\mathrm{Ti}$, and $\mathrm{K}$ elements are present in trace amounts in fly ash and china clays. Occurrence of elements in the composite is due to the reaction china clay with fly ash during sintering process.

The resistivity value of fly ash, china clays, fly ash/china clays composites is presented in Table 2 . From the resistivity data analysis, we are concluded that the resistivity of Fly Ash/china clay (FA60/CC40) composite is more compared with the other prepared composite.

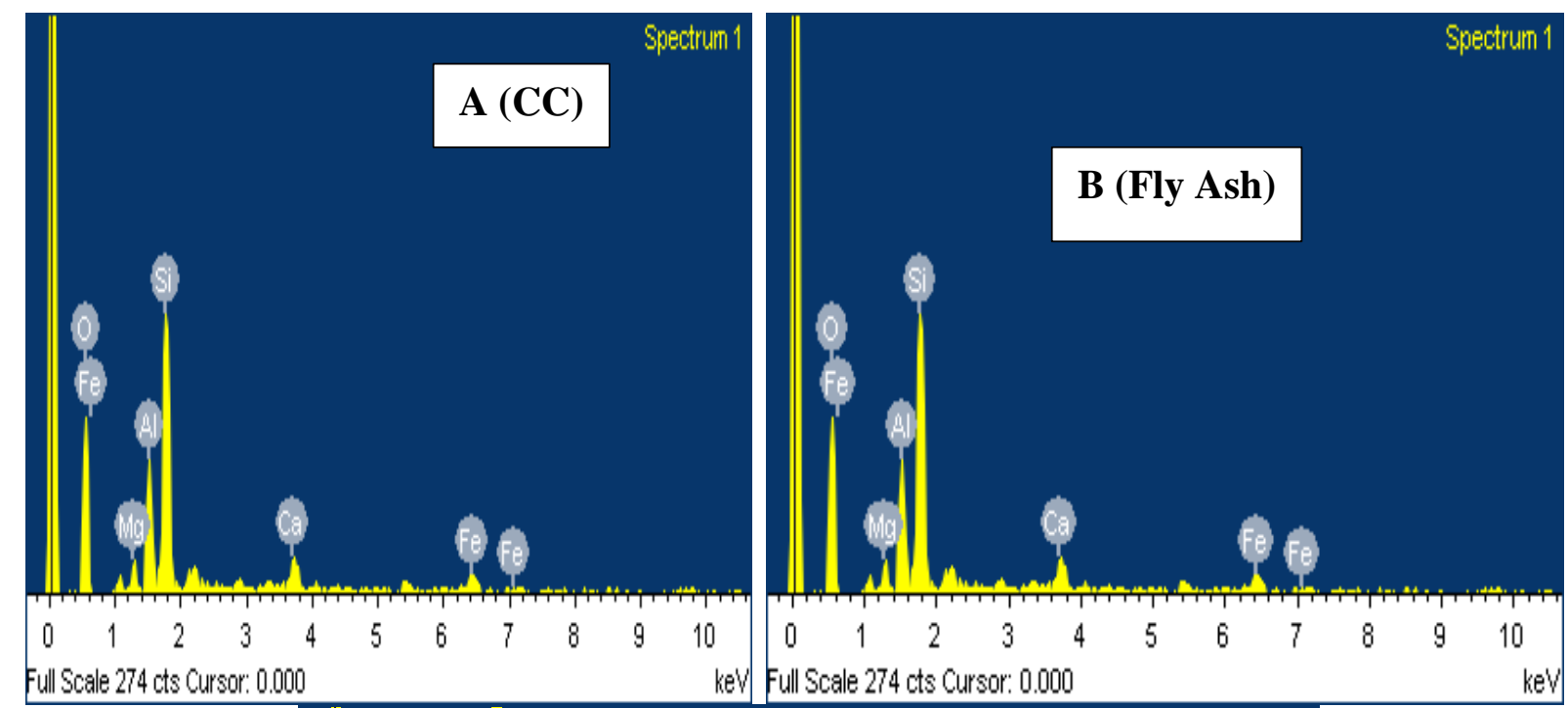

Full Scale 274 cts Cursor: 0.000

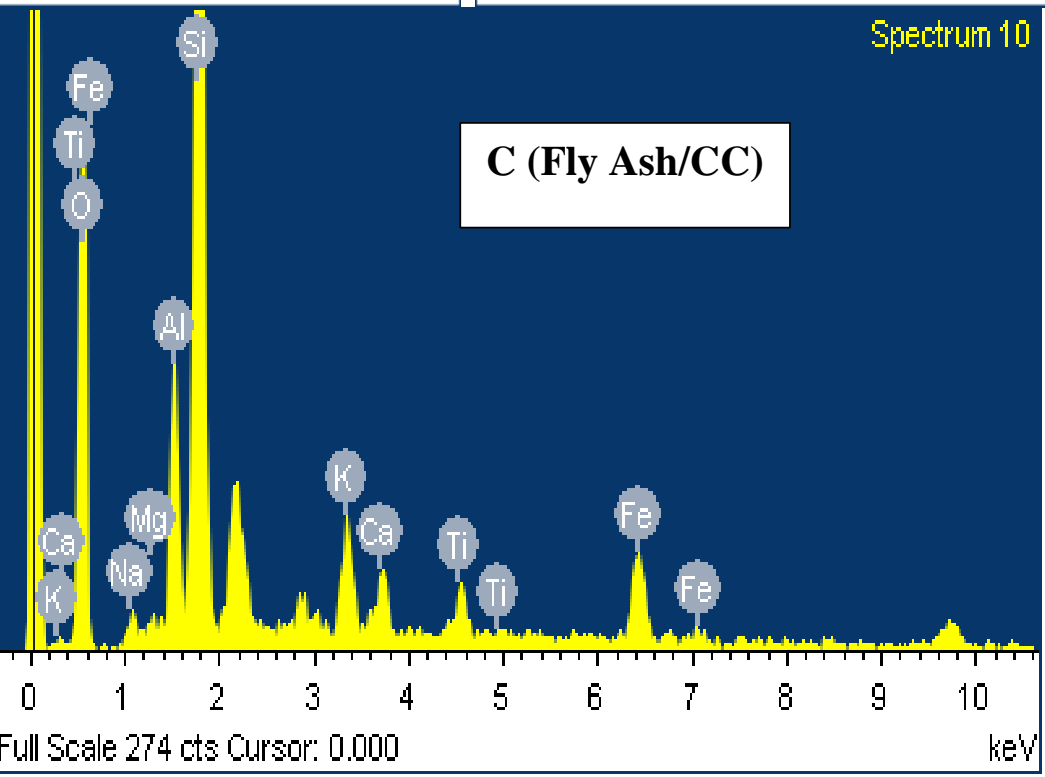

Figure 5. FESEM images of Fly ash (A), China clays (B), Sintered Fly ash/China Clay composite (C) 
Table 2. Resistivity value of fly ash, china clays, fly ash/china clays composites [12]

\begin{tabular}{|c|c|c|}
\hline S.No. & Sample ID & Resistivity( $\Omega \mathbf{m})$ \\
\hline 1 & S0 (FA100:CC0) [20] & $2.85 \times 10^{7}$ \\
\hline 2 & S1 (FA0:CC100) [21] & $0.73 \times 10^{7}$ \\
\hline 3 & S2 (FA90:CC10) at $1200^{\circ} \mathrm{C}$ & $7.36 \times 10^{7}$ \\
\hline 4 & $\mathrm{~S} 2$ (FA80:CC20) at $1200^{\circ} \mathrm{C}$ & $12.1 \times 10^{7}$ \\
\hline 5 & S3 (FA70:CC30) at $1200^{\circ} \mathrm{C}$ & $17.5 \times 10^{7}$ \\
\hline 6 & S4 (FA60:CC40) at $1200^{\circ} \mathrm{C}$ & $39.5 \times 10^{7}$ \\
\hline 7 & S5 (FA50:CC50)at $1200^{\circ} \mathrm{C}$ & $27.03 \times 10^{7}$ \\
\hline
\end{tabular}

Resistivity of the composite (FA60/CC40) is found to be $39.5 \times 107 \Omega \mathrm{m}$, which is 54 times more than the resistivity of pure china clays. This is due to the formation of more amounts mulite phases in the prepared composite. From the results, it concludes that the FA60/CC40 composite is more suitable for preparing an insulator [12]

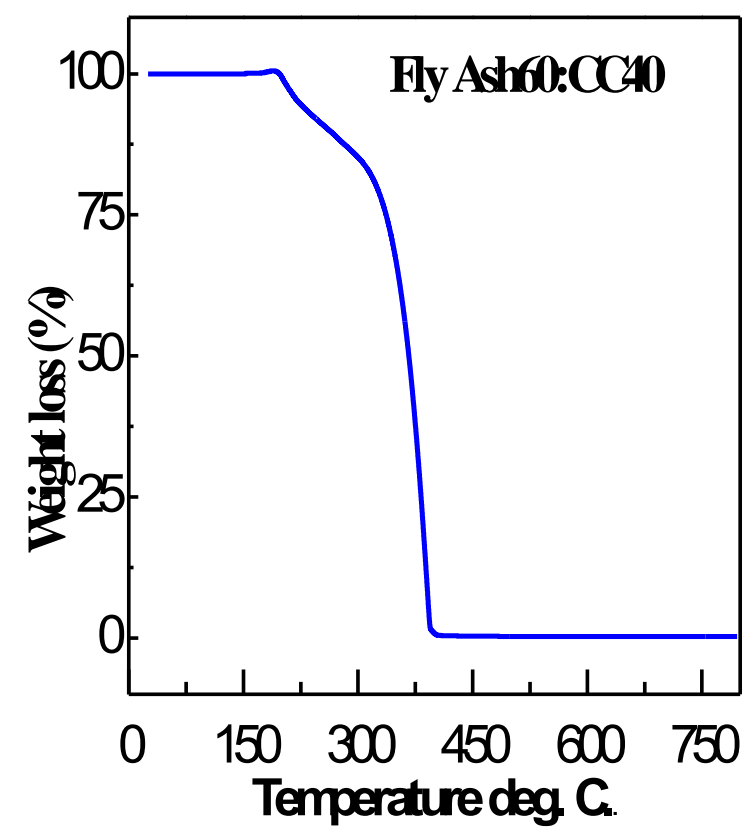

Figure 6. TGA plot of Fly ash/China Clay composite

In TG analysis, the weight loss is estimated for different temperature, ranging between $30-800{ }^{\circ} \mathrm{C}$ and data are plotted as shown in Fig 6. TGA runs are taken one samples, i.e., FA60:CC40 composite (Fig 6). There is a two stage sharp decrease in weight percentage below $360{ }^{\circ} \mathrm{C}$. This is attributed to the loss of dehydroxylation (structural $\mathrm{OH}$-groups) molecules and crystalline mulite phases $[18,19]$.

The frequency dependence dielectric constant of the composite (FA60:CC40) ( $\mathrm{k}$ ) is measured and is plotted (Figure 7). The composite itself gave an expected negative dielectric response at all of the frequencies is investigated. The composite material shows negative dielectric response both in the low and high frequency ranges. A very high dielectric response $(k>100)$ at low frequencies also suggests that there is a polarization of space charge [20].

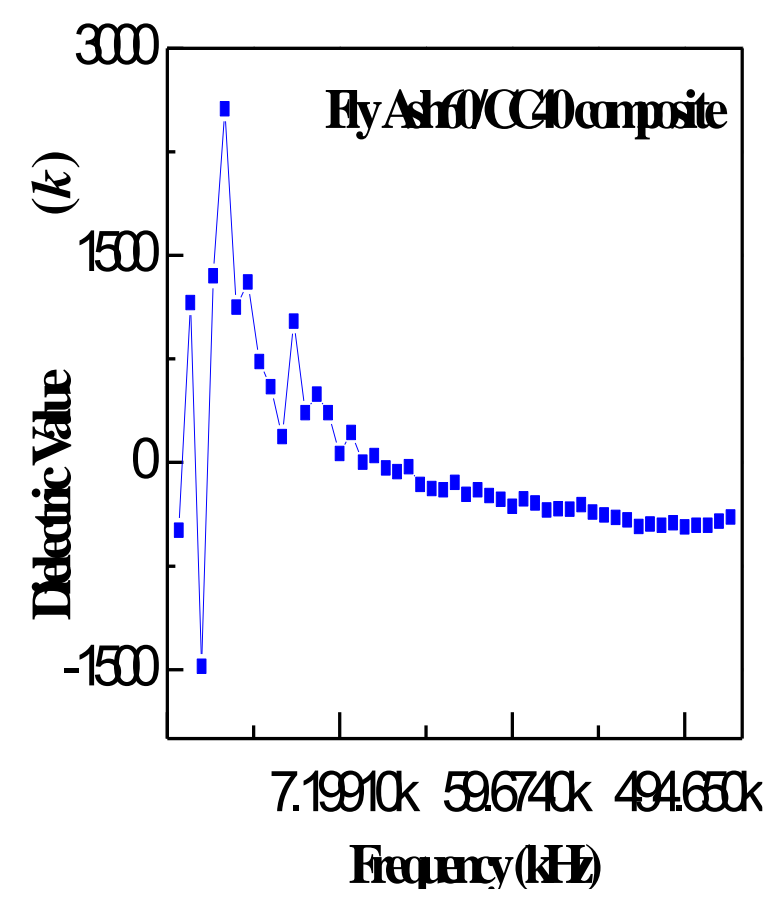

Figure 7. Dielectric plot of Fly ash/China Clay composite (C) [23] 
As it is very desirable to obtain a high dielectric response at higher frequencies, it is also interesting to note that at much higher frequencies $(>100 \mathrm{kHz})$ the dielectric response of composite is more negative. This behavior may originate from a suppressed space charge in the composite system. The dielectric constant of FA60:CC40 increases in presence $\mathrm{K}+$ and $\mathrm{Na}+$ cations and decreases when they are replaced by $\mathrm{Ca} 2+, \mathrm{Mg} 2+$, and $\mathrm{Ba} 2+$ cations. Dielectric property is determined by the concentration and mobility of $\mathrm{K}+$ and or $\mathrm{Na}+$ ions in this phase. On the other hand, mullite phase has a vital role on dielectric properties. XRD analyses indicated that the composite showed higher percentage of crystalline phases, which can explain the property. The sample shows a particularly pronounced effect and may serve as a new avenue toward materials for electromagnetic cloaking and extremely low loss communications applications [2023].

\section{Conclusions}

Electrical insulating materials are prepared from fly ash and china clay successfully by solid state route through sintering process. The structure and morphology of electrical insulating materials are studied using different characterization technique. The microstructure of the insulating materials shows compacted-shaped with crystalline phase. Conversion of irregular spherical present in the fly ash has been transformed to compacted crystalline phase during the formation of the insulating materials. Together with microstructural observation, FESEM/EDS analyses show the presence of elements which indicates occurrence of reaction during the sintering process. The maximum electrical resistivity is found to be $15 \Omega \mathrm{m}$. XRD pattern has clearly shown the formation of mullite and quartz phases. There is a marked difference observed in the FTIR spectrums. The numbers of peaks of as-prepared samples are described the formation of new bonds within the phases. TGA curves have revealed, for $\mathrm{FA} / \mathrm{CC}$ composite there is occurred a gradual degradation of material in the temperature range (200$360{ }^{\circ} \mathrm{C}$ ). Frequency dependence results show that there is a negative constant dielectric value observed from $7.2 \mathrm{kHz}$ to $500 \mathrm{kHz}$. This is due to due to dielectric relaxation.

\section{References}

[1] N.S. Pandian, C. Rajasekhar, A. Sridharan, Studies of the Specific Gravity of Some Indian Coal Ashes, Journal of testing and evaluation, 26 (1998) 177-186. [DOI]

[2] N.S. Pandian, Fly ash characterization with reference to geotechnical applications. Journal of the Indian Institute of Science, 84 (2004) 189-216.

[3] M. Ahmaruzzaman, A review on the utilization of fly ash, Progress in energy and combustion science, 36 (2010) 327-363. [DOI]

[4] L. Wang, G. Hu, F. Lyu, T. Yue, H. Tang, H. Han, Y. Yang, R. Liu, W. Sun, Application of red mud in wastewater treatment. Minerals, 9 (2019) 1-22 [DOI]

[5] S. Sushil, V.S. Batra, Catalytic applications of red mud, an aluminium industry waste: $A$ review, Applied Catalysis B: Environmental, 81 (2008) 64-77. [DOI]

[6] C.L. Goldsmith, A. Malczcwski, J.J. Yao, S. Chen, J. Ehmk, D.H. Hinzel, RFMEMS-Based Tunable Filters, International Journal of RF and Microwave Computer-Aided Engineering, 9 (1999) 362.

[7] G. Subramanyam, F.V. Keuls and F. A. Miranda, Novel K-band Tunable Microstrip vband Pass Filter using Thin Film HTS/Ferroelectric/Dielectric Multilayer Configuration, IEEE MTT-S International Microwave Symposium sponsored by the Institute of Electrical and Electronics Engineers, 8 (1998) 1-8.

[8] A. Tombak, J.P. Maria, F.T. Ayguavives, Z. Jin, G.T. Stauf, A.I. Kingon, A. Mortazawi, Voltagecontrolled RF filters employing thin-film barium-strontium-titanate tunable capacitors, IEEE Transactions on Microwave Theory and Techniques, 51 (2003) 462-467. [DOI]

[9] J. Nath, D. Ghosh, J.P. Maria, A.I. Kingon, W. Fathelbab, D. Paul, F.Z. Michael, B. Steer, An electronically tunable microstrip bandpass filter using thin-film Barium-Strontium-Titanate (BST) varactors, IEEE transactions on microwave theory and techniques, 53 (2005) 2707-2712. [DOI]

[10] L.Y.V. Chen, R. Forse, D. Chase, R.A. York, Analog tunable matching network using integrated thin-film BST capacitors, IEEE MTT$S$ International Microwave Symposium Digest (IEEE Cat. No.04CH37535), 1 (2004) 261-264. [DOI]

[11] F.H. Wee1, F. Malek, S. Sreekantan, A.U. AlAmani, F. Ghani1, K.Y. You, Investigation of the characteristics of barium strontium titanate (BST) dielectric resonator ceramic loaded on 
array antennas, Progress in Electromagnetics Research, 121 (2011) 181-213. [DOI]

[12] M.K. Panigrahi, P. Kumar, B. Barik, D. Behera, S.K. Mohapatra, H. Jha, (2016) Frequency Dependency of Developed Dielectric Material from Fly Ash: An Industrial Waste, In. 20 ${ }^{\text {th }}$ National Conference on Nonferrous Minerals and Metals, 8-9th July 2016; Eds. Rakesh Kumar, K.K.Sahu \& Abhilash, 143.

[13] T.R. Naik, R. Kumar, B.W. Ramme, R.N. Kraus, Effect of High-Carbon Fly Ash on the Electrical Resistivity of Fly Ash Concrete Containing Carbon Fibers, $2^{\text {nd }}$ In Proceedings of the Conference on Sustainable Construction Materials and Technologies, 3 (2010) 18751886

[14] Y.V. Khedekar, R.N. Singru, Electrical Conductivity and Thermogravimetric Analysis of Polypyrrole: A Conducting Polymer Composite of Fly Ash, International Journal of Advanced Science and Technology, 29 (2020) 3078.

[15] R Dewi1, H Agusnar, Z Alfian, Tamrin, Characterization of Technical Kaolin using XRF, SEM, XRD, FTIR and its Potentials as Industrial Raw Materials, In Journal of Physics: Conference Series, IOP Publishing, 1116 (2018) 1-7. [DOI]

[16] B.J. Saikia, G.K Rao, P. Sarathy, Fourier Transform Infrared Spectroscopic Characterization of Kaolinite from Assam and Meghalaya, North Eastern India, International Journal of Modern Physics, 1 (2010) 206-210. [DOI]

[17] R.P. dos Santos, J. Martins, C. Gadelha, B. Cavada, A.V. Albertini, F. Arruda, M. Vasconcelos, E. Teixeira, F. Alves, J.L. Filho, V. Freire, Coal Fly Ash Ceramics: Preparation, Characterization, and Use in the Hydrolysis of Sucrose, Scientific World Journal, 2014 (2014) 1-8 [DOI]

[18] H. Wang, C. Li, Z. Peng, S. Zhang, Characterization and thermal behavior of kaolin, Journal of Thermal Analysis and Calorimetry, 105 (2011) 157-160. [DOI]

[19] D.L.Y. Kong, J.G. Sanjayan, Effect of Elevated Temperatures on Geopolymer Paste, Mortar and Concrete, Cement and concrete research, 40 (2010) 334-339. [DOI]

[20] P. Barber, S. Balasubramanian, Y. Anguchamy, S. Gong, A. Wibowo, H. Gao, H.J. Ploehn, H.-C. Zur Loye, Review Polymer Composite and
Nanocomposite Dielectric Materials for Pulse Power Energy Storage, Materials, 2 (2009) 1697-1733. [DOI]

[21] N. Singh Mehta, P.K. Sahu, P. Tripathi, R.P. Manas, R. Majhi, Influence of alumina and silica addition on the physico-mechanical and dielectric behavior of ceramic porcelain insulator at high sintering temperature, Boletín de la sociedad española de cerámica y vidrio, 57 (2018) 151-159. [DOI]

[22] Y. Lv, M. Rafiq, C. Li, B. Shan, Study of dielectric breakdown performance of transformer oil based magnetic nanofluids, Energies, 10 (2017) 1-21. [DOI]

[23] K. Belhouchet, A. Bayadi, H. Belhouchet, M. Romero, Improvement of Mechanical and Dielectric Properties of Porcelain Insulators using Economic Raw Materials, Boletín de la Sociedad Española de Cerámica y Vidrio, 58 (2019) 28-37. [DOI]

\section{Acknowledgements}

The author conveys their sincere thanks to GIET, Gunupur, Rayagada, Odisha, India for providing Lab facilities to do the research work. The author is also like to thank the CRF, IIT Kharagpur for their providing testing facilities.

\section{Funding \\ NIL.}

\section{Does the Article Screened for Similarity?} Yes.

\section{Data Availability}

No additional data are available.

\section{Conflict of interest}

The authors declare that they have no actual or potential conflict of interest, including financial, personal or other relationships with people or organizations that could have inappropriately influenced this work.

\section{About the License}

(C) The author 2021. The text of this article is open access and licensed under a Creative Commons Attribution 4.0 International License 